\title{
Concentrations of connective tissue growth factor in patients with nonalcoholic fatty liver disease: Association with liver fibrosis
}

\author{
Yasar Colak $^{\mathrm{a}, *}$, Ebubekir Senates $^{\mathrm{b}}$, Ender Coskunpinar $^{\mathrm{c}}$, Yasemin Musteri Oltulu $^{\mathrm{c}}$, Ebru Zemheri ${ }^{\mathrm{d}}$, \\ Oguzhan Ozturk $^{\mathrm{a}}$, Levent Doganay ${ }^{\mathrm{a}}$, Banu Mesci ${ }^{\mathrm{e}}$, Yusuf Yilmaz ${ }^{\mathrm{f}, \mathrm{g}}$, Feruze Yilmaz Enc $^{\mathrm{a}}$, \\ Safak Kiziltas ${ }^{\mathrm{a}}$, Celal Ulasoglu ${ }^{\mathrm{a}}$ and Ilyas Tuncer ${ }^{\mathrm{a}}$ \\ ${ }^{a}$ Department of Gastroenterology, Istanbul Medeniyet University, Medical Faculty, Istanbul, Turkey \\ ${ }^{\mathrm{b}}$ Department of Gastroenterology, Dicle University Medical Faculty, Diyarbakir, Turkey \\ ${ }^{\mathrm{c}}$ Department of Molecular Medicine, Institute of Experimental Medicine (DETAE), Istanbul University, Istanbul, \\ Turkey \\ ${ }^{\mathrm{d}}$ Department of Pathology, Istanbul Medeniyet University, Medical Faculty, Istanbul, Turkey \\ ${ }^{\mathrm{e}}$ Department of Internal Medicine, Istanbul Medeniyet University, Medical Faculty, Istanbul, Turkey \\ ${ }^{\mathrm{f}}$ Department of Gastroenterology, Marmara University School of Medicine, Istanbul, Turkey \\ ${ }^{\mathrm{g}}$ Institute of Gastroenterology, Marmara University, Istanbul, Turkey
}

\begin{abstract}
Aim: In this study, we aimed to investigate the relationship between the histological fibrosis stage of nonalcoholic fatty liver disease (NAFLD) and serum connective tissue growth factor (CTGF) to determine the usefulness of this relationship in clinical practice.

Methods: Serum samples were collected from 51 patients with biopsy-proven NAFLD and 28 healthy controls, and serum levels of CTGF were assayed by ELISA.

Results: Levels of CTGF were significantly higher in patients with NAFLD compared with controls $(P=0.001)$. The serum CTGF levels were significantly increased, that correlated with histological fibrosis stage, in patients with NAFLD [in patients with no fibrosis (stage 0) $308.2 \pm 142.9$, with mild fibrosis (stage 1-2) 519.9 \pm 375.2 and with advanced fibrosis (stage 3-4) $1353.2 \pm 610 \mathrm{ng} / \mathrm{l}, P<0.001]$. Also serum level of CTGF was found as an independent predictor of histological fibrosis stage in patients with NAFLD $(\beta=0.662, t=5.6, P<0.001)$. The area under the ROC curve was estimated 0.931 to separate patients with severe fibrosis from patients with other fibrotic stages.

Conclusion: Serum levels of CTGF may be a clinical utility for distinguishing NAFLD patients with and without advanced fibrosis.
\end{abstract}

Keywords: Nonalcoholic fatty liver disease (NAFLD), nonalcoholic steatohepatitis (NASH), connective tissue growth factor (CTGF), fibrosis

\section{Introduction}

Nonalcoholic fatty liver disease (NAFLD) is the hepatic manifestation of metabolic syndrome and is one

\footnotetext{
* Corresponding author: Yasar Colak, Department of Gastroenterology, Istanbul Medeniyet University, Medical Faculty, 34730, Istanbul, Turkey. Tel.: +90 21656640 00; Fax: +90 21656640 23; E-mail: dryasarcolak@yahoo.com.
}

of the most common causes of chronic liver disease worldwide [1,2]. In general, the disease is divided into two sub-groups as simple steatosis and nonalcoholic steatohepatitis (NASH). It is well known that the NASH may progress to advanced fibrotic disease and lead to cirrhosis. In this aspect, identifying advanced fibrosis and distinguishing NAFLD as simple steatosis or NASH are clinically important. The liver biopsy, as an invasive method, is still the gold standard for diagnosis of NAFLD and differentiation of NASH. 
Connective tissue growth factor (CTGF) is a cysteine-rich member of heparin-binding proteins and it is associated with extracellular matrix. It has a vital role in chondrogenesis, angiogenesis and skeletal system development during embryonic period [3]. Also it plays a crucial role in some important cellular functions as cell proliferation and differentiation [4,5], extracellular matrix synthesis [6], cell adhesion to extracellular matrix [7,8] and cell migration [7]. It has been shown that CTFG induces the production of extracellular matrix by stimulating transcription of type 1 collagen [8]. Also recent reports have shown higher CTFG expression in cases with increased connective tissue in lungs, bowel, kidney and liver [9-15]. Also another recent study has found increased expression of CTFG correlating with severity of fibrosis independent of inflammation in patients with chronic hepatitis $C$ [12].

In this observational, case-control study, we investigated serum levels of CTGF in patients with NAFLD and examined the association between levels of this molecule with clinical, biochemical and histological fibrosis scores.

\section{Methods}

\subsection{Study subjects}

The study protocol was approved by our local ethics committee and all volunteers gave written informed consent. Fifty patients with biopsy proven NAFLD (23 men and 27 women; mean age $44.4 \pm 10,7$ years) and 28 healthy comparison subjects (13 men and 15 women; mean age, $42,7 \pm 8,7$ years) were included in the study. The patients who had admitted to our clinic in last one year with high transaminase levels and with diagnosis of NAFLD in histopathological evaluation were included into the study. All of them had ALT elevations for at least 6 months, and had no history of any hepatotoxic drugs, hormone replacement therapy or any herbal products and no alcohol consumption more than $20 \mathrm{~g} /$ day. History of alcohol or hepatotoxic drugs (including herbals), viral serology, autoimmune markers, iron status, ceruloplasmin, serum and 24-hours urinary copper, alpha-1 antitrypsin levels, thyroid functions, eye examination (Kayser-Fleischer rings), ultrasonography (for exclusion of malignancy and/or cholestatic diseases) were assessed. The patients having hepatosteatosis in ultrasonography were followed up for next 6 months. An ultrasonography (US)-guided liver biopsy was performed to the patients with high transam- inase levels persisting after sixth month and those having NAFLD diagnosis were enrolled into the study. Prior to liver biopsies all patients gave written informed consent. The local ethical committee gave approval to the study. The healthy control group had no illness, no alcohol consumption, no drug or herbal substances, no history of previous liver diseases, negative for viral hepatitis serology, and having normal liver US.

\subsection{Clinical assessment}

A complete physical examination was performed to all subjects. Anthropometric assessment of height and weight were measured, body mass index (BMI) $(\mathrm{kg} / \mathrm{m} 2)$ was calculated and waist circumference $(\mathrm{cm})$ was measured. Blood pressures were measured after a ten minutes rest in a quiet room. Venous blood samples were taken in the morning after a twelve hours fasting. Complete blood counts and biochemical parameters were assessed using standard methods. The serum samples were centrifuged for 10 minutes at $2500 \mathrm{~g}$ and serum was stored at $-80 \mathrm{C}$ until analysis. The Adult Treatment Panel III [16] for metabolic syndrome and American Diabetes Association [17] criteria was used for diabetes mellitus diagnosis. HOMA-IR index [fasting plasma insulin $(\mathrm{mU} / \mathrm{ml}) \mathrm{x}$ fasting plasma glucose $(\mathrm{mg} / \mathrm{dl}) / 405.23]$ was used for determining insulin resistance. All ultrasonographic examinations and ultrasound guided percutaneous liver biopsies were performed by the same radiologist.

Serum CTGF levels were measured duplicate by enzyme-linked immunosorbent assay (Uscn Life Science Inc, Wuhan, China) kit according to the manufacturer's instructions. The minimum detectable value was $11.4 \mathrm{ng} / \mathrm{l}$. The intra-assay and the inter-assay coefficients of variation for CTGF were $<10 \%$ and $<12 \%$, respectively. All biochemical tests were performed in a blind manner.

\subsection{Histological analysis}

All patients in this study underwent US-guided percutaneous liver biopsy. The liver specimens obtained were accepted sufficient if the length of the tissues were greater than $2 \mathrm{~cm}$ and/or showing more than six portal areas in histological examination. The liver specimens were stained with hematoxylin-eosin, Masson's trichrome and reticulin silver stains. They are scored and evaluated by an experienced hepatopathologist blind to the clinical status of the patients. Histological evaluation was done according to the NAFLD 
Table 1

Clinical and biochemical characteristics of the nonalcoholic fatty liver disease (NAFLD) patients and healthy controls

\begin{tabular}{lccc}
\hline & NAFLD group $(n=50)$ & Healthy Controls $(n=28)$ & P value \\
\hline Gender (male/female) & $23 / 27$ & $13 / 15$ & $>0.05$ \\
Age $($ years) & $44.4 \pm 10.7$ & $42.7 \pm 8.7$ & $>0.05$ \\
BMI $\left(\mathrm{kg} / \mathrm{m}^{2}\right)$ & $31.7 \pm 5.6$ & $24.7 \pm 4.1$ & $<0.001$ \\
Waist circumference $(\mathrm{cm})(\mathrm{men} /$ women) & $109 \pm 6 / 99.3 \pm 5$ & $88.3 \pm 4.3 / 81 \pm 1.1$ & $<0.001$ \\
Sedimentation $(\mathrm{mm} / \mathrm{hr})$ & $14 \pm 9.7$ & $10.7 \pm 6.4$ & $>0.05$ \\
C-reactive protein $(\mathrm{mg} / \mathrm{L})$ & $5.3 \pm 4.1$ & $3.3 \pm 2.5$ & 0.034 \\
White blood cells $\left(\times 10^{9} / \mathrm{L}\right)$ & $6.98 \pm 2.45$ & $7.25 \pm 1.44$ & $>0.05$ \\
Hemoglobin A1c $(\%)$ & $5.95 \pm 1$ & $5.21 \pm 0.2$ & $<0.001$ \\
HOMA-IR & $2.8 \pm 1.86$ & $1.35 \pm 0.53$ & $<0.001$ \\
Total cholesterol $(\mathrm{mmol} / \mathrm{L})$ & $5.31 \pm 1.53$ & $4.59 \pm 1.13$ & $<0.001$ \\
Triglycerides $(\mathrm{mmol} / \mathrm{L})$ & $2.30 \pm 2$ & $1.09 \pm 0.47$ & $<0.001$ \\
LDL cholesterol $(\mathrm{mmol} / \mathrm{L})$ & $3.58 \pm 1.04$ & $3 \pm 0.64$ & 0.013 \\
HDL cholesterol $(\mathrm{mmol} / \mathrm{L})$ & $2.74 \pm 0.23$ & $1.29 \pm 0.2$ & $>0.05$ \\
AST $(\mathrm{U} / \mathrm{L})$ & $39.9 \pm 21.9$ & $20.9 \pm 5$ & $<0.001$ \\
ALT $(\mathrm{U} / \mathrm{L})$ & $55.7 \pm 33.2$ & $15.5 \pm 4.2$ & $<0.001$ \\
CTGF(ng/l) & $519.9 \pm 436.2$ & $288.5 \pm 97.7$ & 0.001 \\
Metabolic syndrome (\%) & $63 \%$ & 0 & \\
\hline
\end{tabular}

Normal values in laboratory tests: Sedimentation $(0-20 \mathrm{~mm} / \mathrm{hr})$; C-reactive protein $(<8 \mathrm{mg} / \mathrm{L})$; white blood cell count $\left(4-10 \times 10^{9} / \mathrm{L}\right)$; HbAlc $(4.3-5.8$ proportion of total hemoglobin); total cholesterol $(2.6-5.2 \mathrm{mmol} / \mathrm{L})$; triglyceride (0.7-1.7 mmol/L); LDL cholesterol (1-3.37 mg/dl); HDL cholesterol ( $>0.9 \mathrm{mmol} / \mathrm{L})$; AST (5-32 U/L); ALT (5-38 $\mathrm{U} / \mathrm{L})$; BMI, HOMA-IR, CTGF and metabolic syndrome are described in the text.

scoring system recommended by National Institute of Diabetes and Digestive and Kidney Diseases NASH Clinical Research Network [18]. Hepatic steatosis was graded from 1 to 3 according to the steatosis ratio as $5-33 \%, 33-66 \%$ and $>66 \%$ representing score 1,2 and 3 respectively. Lobular inflammation was defined as an overall assessment of all inflammations; no foci as score $0,<2$ foci per $\mathrm{x} 200$ field as score 1 , two-four foci per $\mathrm{x} 200$ field as score 2 , more than 4 foci per $\mathrm{x} 200$ field as score 3 . Ballooning scoring was defined as score 0 if there is no ballooning of hepatocytes, score 1 if there are few and score 2 if there are numerous ballooning. Fibrosis was staged as follows: stage 0 , no liver fibrosis; stage 1, perisinusoidal or periportal fibrosis; stage 2, perisinusoidal and portal/periportal fibrosis; stage 3 , bridging fibrosis and stage 4 , cirrhosis. Histologically, total NASH score was calculated as a sum of steatosis (1-3), lobular inflammation (0-3) and ballooning (0-2). The total NASH score was defined as 0-2 as simple steatosis, 3-4 as borderline NASH, 5 or greater as definitive NASH [18].

\subsection{Statistical analysis}

Data were processed on a personal computer and analyzed using SPSS 16.0 (SSPS Inc., Chicago, IL, USA). Normally distributed continuous variables were presented as mean \pm standard deviation; skewed continuous variables were characterized by medians and interquartile ranges. The student $t$ test was used in the evaluation of the difference between the two averages of the independent groups. Differences in the levels of CTGF among the groups were determined by one-way analysis of variance followed by Bonferroni multiple comparison post-hoc test. Categorical data were analyzed by using the $x^{2}$ test. Spearman rank correlation was used to examine the relationship between variables. Multiple linear regression analysis was performed to evaluate the independence of the association between CTGF levels, clinical, biochemical and histological parameters of liver injury in NAFLD patients. The covariates for these analyses were age, waist circumference, AST, histological steatosis scores and fibrosis stages. Receiver operating characteristic (ROC) curve analysis was used to identify the optimal cutoff value of CTGF for distinguishing patients with severe fibrotic from no and mild or moderate fibrotic NAFLD. The $\mathrm{P}$ values less than 0.05 were considered statistically significant.

\section{Results}

The main clinical and laboratory characteristics of the patients and controls are described in Table 1 . The age and gender distribution rates were similar between patients with NAFLD and controls. Body mass index, waist circumference, C-reactive protein, HOMAIR index, total and LDL cholesterols, triglycerides and transaminase levels in patients with NAFLD were significantly higher than controls (Table 1). As expected, 


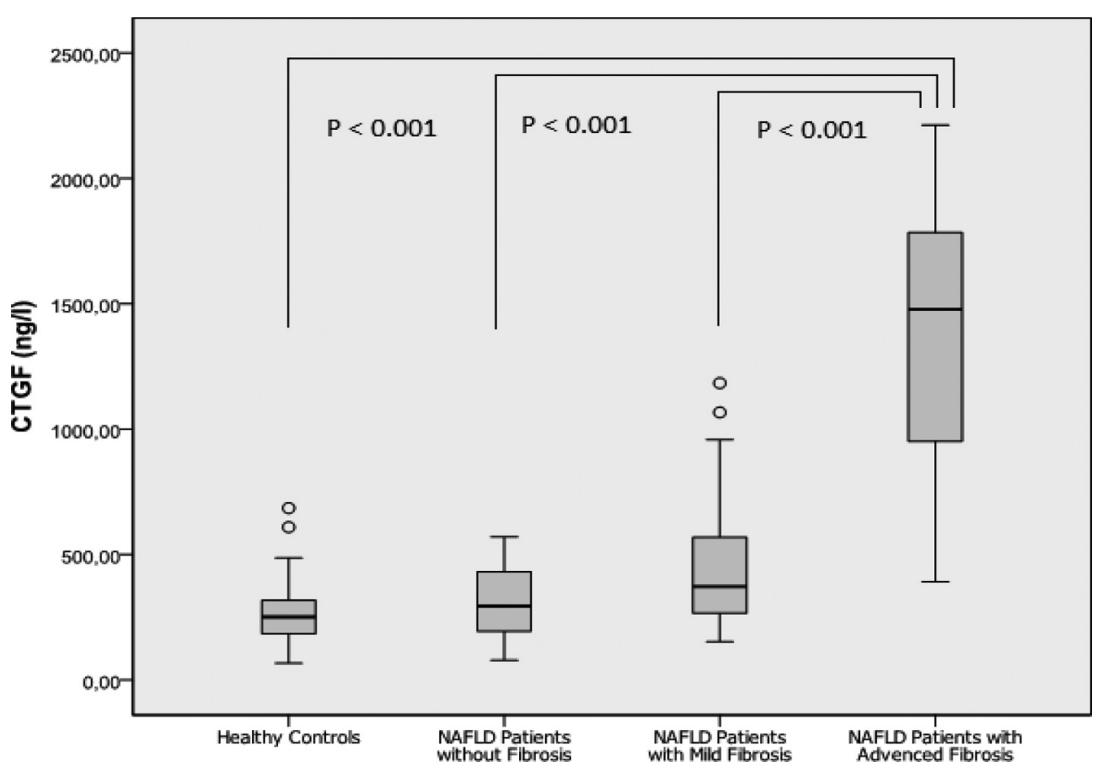

Fig. 1. Serum connective tissue growth factor (CTGF) levels in healthy controls and patients with nonalcoholic fatty liver disease according to fibrosis stage (Mild fibrosis: fibrosis stage $=1-2$, Advanced fibrosis: fibrosis stage $=3-4$ ).

the prevalence of MS and diabetes mellitus in patients with NAFLD was $63 \%$ and 30\%, respectively [19-21].

Levels of CTGF in patients with NAFLD were significantly higher than those of the controls $(P<0.001)$ (Table 1). Six (12\%) patients had simple steatosis, 16 (32\%) patients had borderline NASH and $28(56 \%)$ patients had definitive NASH in the NAFLD group. As assessed by one-way analysis of variance, circulating CTGF levels were significantly different across the four study subgroups $(P<0.01)$. Specifically, the Bonferroni multiple comparison post-hoc test indicated that concentrations of CTGF were significantly higher in patients with definitive NASH $(720 \pm 609 \mathrm{ng} / \mathrm{l}, P<$ $0.001)$ compared with controls (288.5 $\pm 97.7 \mathrm{ng} / \mathrm{l})$. There was no difference between other subgroups [borderline NASH $(491 \pm 431 \mathrm{ng} / \mathrm{l})$ and simple fatty liver $(416 \pm 280 \mathrm{ng} / \mathrm{l})]$.

NAFLD cases were analyzed according to their subgroups by fibrosis score in liver, no fibrosis (stage 0 ) $(n=18)$, mild fibrosis (stage 1-2) $(n=22)$ and advanced fibrosis (stage $3-4)(n=10)$ and the serum levels of CTGF were increased parallel to increased fibrosis $(308.2 \pm 142.9 \mathrm{ng} / \mathrm{l}, 519.9 \pm 375.2 \mathrm{ng} / \mathrm{l}, 1353.2$ $\pm 610 \mathrm{ng} / \mathrm{l}$, respectively) and the differences between all groups were statistically significant $(P<0.001)$ (Fig. 1). The post-hoc analysis of serum CTGF levels of severe fibrosis subgroup were significantly higher than all other subgroups $(P<0.001)$ (Fig. 1). After separation of severe fibrosis subgroup, there was no difference between other subgroups.
In correlation analysis, serum CTGF levels had positive correlations with age $(r=0256, P=0.025)$, waist circumference $(r=0295, P=0.009)$, AST $(r=0.361, P=0.002)$, NASH scores $(r=0334$, $P=0.018)$ and fibrosis scores $(r=0566, P<0.001)$ (Fig. 2).

Histological steatosis, lobular and portal inflammation had no correlation with serum levels of CTGF. In addition, stepwise multiple regression analysis, including all the correlated parameters, determined that the serum CTGF level in patients with NAFLD was an independent predictor for determining the stage of histological fibrosis $(\beta=0662, t=5.6, P<0.01)$.

For distinguishing advanced fibrosis from other NAFLD subgroups, analysis of CTGF levels with a threshold of $904 \mathrm{ng} / \mathrm{l}$ revealed an area under the ROC curve as $93.1 \%$ (Fig. 3). For the same threshold value for this differentiation of advanced fibrosis had positive predictive value as $72.7 \%$, negative predictive value as $94.7 \%$, sensitivity as $92.3 \%$ and specificity as $80 \%$.

\section{Discussion}

In the present study, (a) serum CTGF was significantly higher in patients with NAFLD compared with controls, (b) serum CTGF was significantly higher in patients with severe fibrosis compared with no or mild fibrosis stages, (c) there was a significant correlation between serum CTGF levels and NASH scores and fi- 


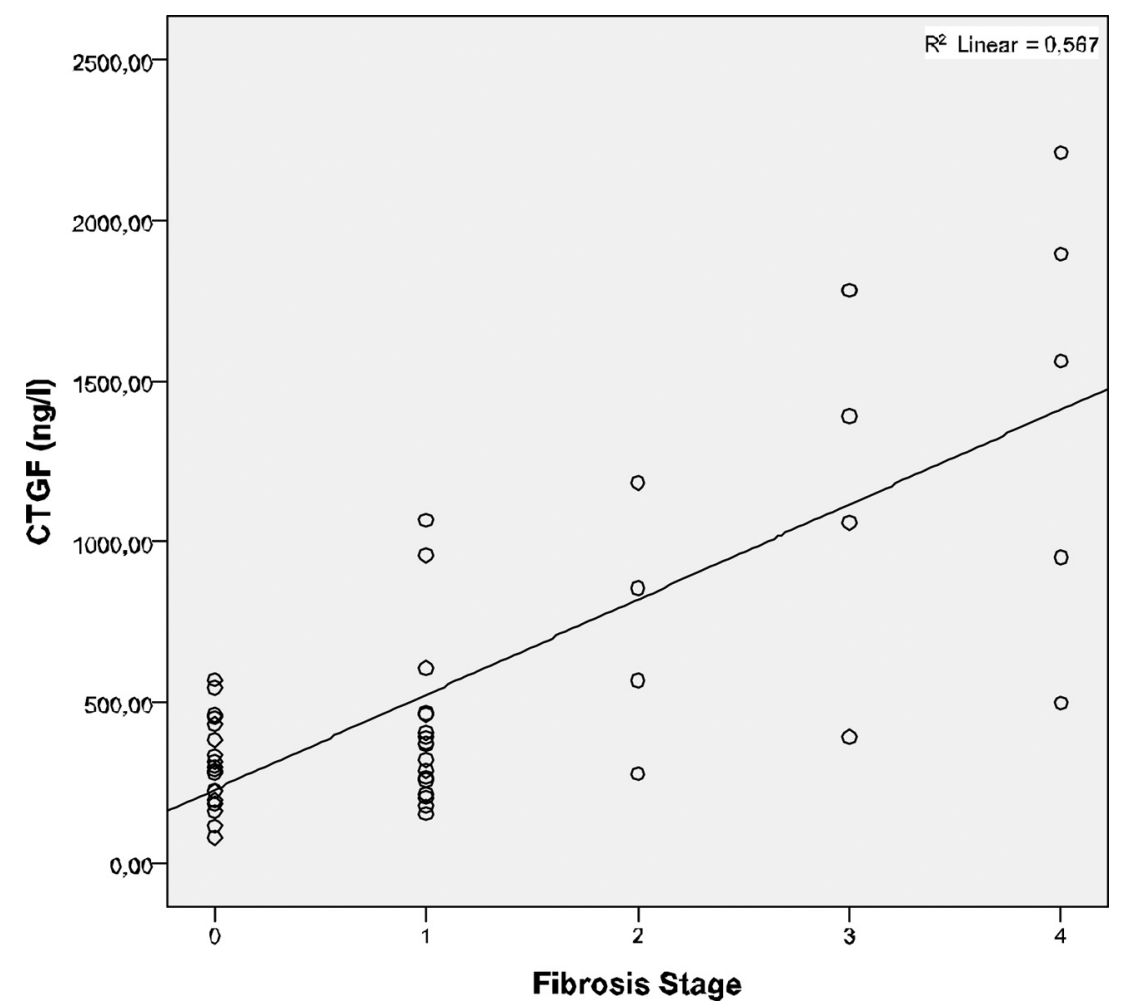

Fig. 2. Relation between serum connective tissue growth factor (CTGF) levels and fibrosis stage in patients with nonalcoholic fatty liver disease.

brosis stages in patient with NAFLD and (d) serum CTGF level was found to be an independent predictor of histological fibrosis stage in patients with NAFLD.

In recent studies, it is shown that CTGF expressed by hepatocytes had a stimulating effect together with the transforming growth factor beta (TGF- $\beta$ ) which is an important mediator of liver fibrogenesis on the formation of extracellular matrix by hepatic stellate cells [22]. In a study, Zhang et al. indicated that the stage of fibrosis in patients with chronic hepatitis was positively correlated with serum CTGF levels [13]. Recently, Kovalenko and his colleagues reported a study showing significantly higher serum CTGF levels in patients with chronic hepatitis $\mathrm{C}$ compared to healthy controls $(P<$ 0.001) [23]. They found that CTGF levels showed a peak in advanced stage of fibrosis which was similar to our results. There was no correlation between serum CTGF levels and histological necroinflammatory score of HCV cases in the same study. Hora et al. reported a study observing CTGF expression in chronic HCV cases [12]. Similar to Kovalenko's study, they found an increase in CTGF expression parallel to increased fibrosis, but not correlating with necroinflammation level. Different than these studies our results showed a correlation between disease stage and serum CTGF lev- els. This difference may be due to our different patient population as NAFLD which has different etiology and pathogenesis than viral hepatitis. In a study by Cayón et al. revealed that non-obese and non-fibrotic NASH patients had significant increase in hepatic gene expression of CTGF compared to non-NASH cases [24]. In the study of Tarantino et al. TGF $\beta$-1 levels were found to be higher in simple steatosis cases compared to patients with chronic hepatitis C [25]. Even though it is not statistically significant, serum CTGF levels were slightly elevated in simple steatosis cases compared to healthy controls in our study. This difference may be associated with free-fatty-acid-induced liver toxicity and subsequent subclinical inflammation in simple steatosis cases [26].

Very recently, the experimental animal model by Wang and colleagues administration of recombinant human monoclonal anti-CTGF antibodies prevented fibrosis formation induced by intraperitoneal injection of CTGF and TGF- $\beta$ [27]. In this sense, in case of confirmation by larger-scale studies, anti-CTGF antibodies may be a potential alternative in the treatment of fibrosis in NAFLD patients.

Several caveats are inherent in this study. First, the causal link between serum CTGF levels and hepatic 


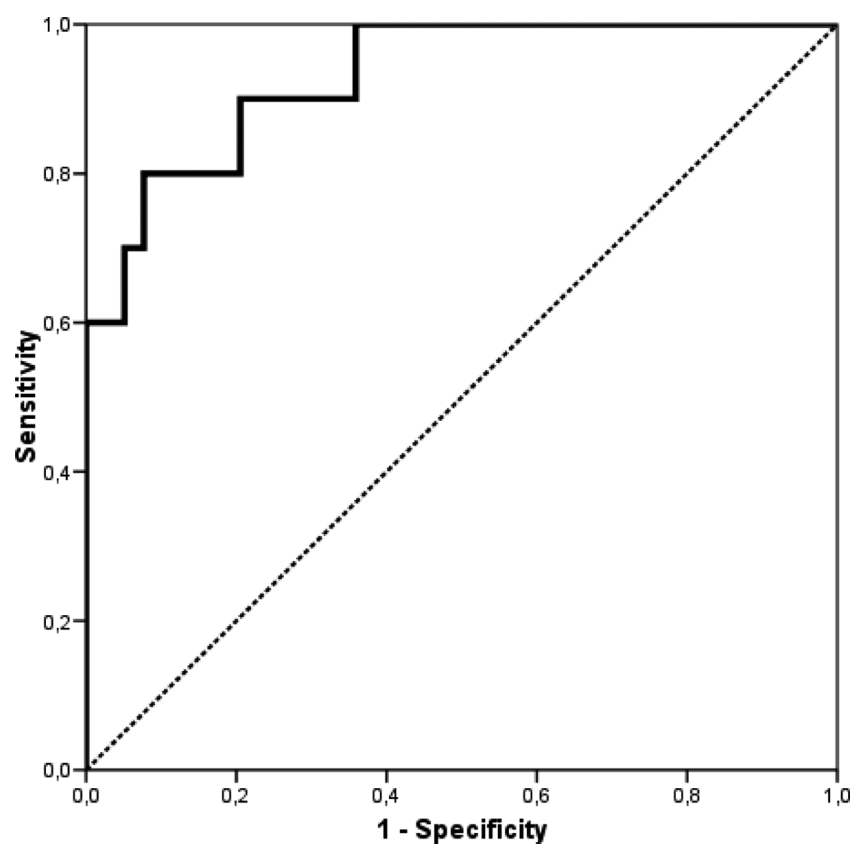

Fig. 3. Receiver operating characteristic (ROC) curve for differentiation of severe fibrosis (stage 3-4) and no or mild fibrosis (stage 0-2) on the basis of serum connective tissue growth factor $(\mathrm{CTGF}$ ) levels (area under the curve $=0.931$ ).

steatosis couldn't be clarified since this was a case control study. To overcome this defect a longitudinal study has to be planned related to the causal relationship between serum CTGF level and liver steatosis. The number of patients, limiting the distinction of our results, was the second issue. Third, the study group consisted of only Turkish ethnicity limiting the generalization of these conclusions. Fourth, for exclusion of NAFLD in control group normal biochemical and ultrasonographic findings were accepted sufficient, and because of ethical concerns, no liver biopsies were performed. Finally, we were unable to study hepatic CTGF expression in liver biopsies. Such data would generally present more information about the source of elevated circulating CTGF levels and the regulation of CTGF in hepatic steatosis.

In conclusion patients with NAFLD, compared to controls, had significant increase in serum CTGF levels and this was correlated with the degree of fibrosis. In addition, serum CTGF level was an indicator of liver fibrosis in patients with NAFLD. As a result, it can be concluded that CTGF level may be a useful parameter in differentiating the advanced fibrotic NAFLD patients from other levels of fibrosis in clinical practice.

\section{Author disclosure statement}

No competing financial interests exist.

\section{References}

[1] Tarantino G, Saldalamacchia G, Conca P, Arena A. Nonalcoholic fatty liver disease: further expression of the metabolic syndrome. J Gastroenterol Hepatol 2007; 22(3): 293-303.

[2] Rafiq N, Younossi ZM. Evaluation and management of nonalcoholic fatty liver disease. Clin Liver Dis 2009; 13: 249-266.

[3] Ivkovic S, Yoon BS, Popoff SN, et al; Connective tissue growth factor coordinates chondrogenesis and angiogenesis during skeletal development. Development 2003; 130: 2779-91.

[4] Kothapalli D, Hayashi N, Grotendorst GR. Inhibition of TGF-beta-stimulated CTGF gene expression and anchorageindependent growth by cAMP identifies a CTGFdependent restriction point in the cell cycle. FASEB J 1998; 12: 1151-61.

[5] Gao RP, Ball DK, Perbal B, Brigstock DR. Connective tissue growth factor induces cfos gene activation and cell proliferation through p44/42 MAP kinase in primary rat hepatic stellate cells. J Hepatol 2004; 40: 431-8.

[6] Safadi FF, Popoff SN, Aswald R, et al; Connective tissue growth factor (CTGF) acts as a downstream mediator of TGFbeta1 to induce mesenchymal cell condensation. J Cell Physiol 2007; 210: 398-410.

[7] Gao R, Brigstock DR. A novel integrin alpha(5)beta(1) binding domain in module 4 of connective tissue growth factor (CCN2/CTGF) promotes adhesion and migration of activated pancreatic stellate cells. Gut 2006; 55: 856-62.

[8] Weinbaum JS, Tranquillo RT, Mecham RP. The matrixbinding domain of microfibril-associated glycoprotein-1 targets active connective tissue growth factor to a fibroblastproduced extracellular matrix. Macromol Biosci 2010; 10: 1338-44.

[9] Günther U, Bateman AC, Beattie RM, et al; Connective tissue growth factor expression is increased in collagenous colitis and coeliac disease. Histopathology 2010; 57: 427-35. 
[10] Ito Y, Aten J, Nguyen TQ, et al; Involvement of Connective Tissue Growth Factor in Human and Experimental Hypertensive Nephrosclerosis. Nephron Exp Nephrol. 2010; 117: 9-20.

[11] Cui MX, Chen XL, Chen C, et al; Effects of rosiglitazone on the expression of connective tissue growth factor in the pulmonary arteries of rats suffering from fibrosis in lung. Zhongguo Ying Yong Sheng Li Xue Za Zhi 2010; 26: 211-5.

[12] Hora C, Negro F, Leandro G, et al; Swiss Hepatitis C Cohort Study Group. Connective tissue growth factor, steatosis and fibrosis in patients with chronic hepatitis C. Liver Int 2008; 28: 370-6.

13] Zhang D, Wang NY, Yang CB, Fang GX, Liu W, Wen J, Luo C. The clinical value of serum connective tissue growth factor in the assessment of liver fibrosis. Dig Dis Sci 2010; 55: 767-74.

[14] Gressner AM, Yagmur E, Lahme B, Gressner O, Stanzel S. Connective tissue growth factor in serum as a new candidate test for assessment of hepatic fibrosis. Clin Chem 2006; 52(9): 1815-57.

[15] Gressner OA, Gressner AM. Connective tissue growth factor: a fibrogenic master switch in fibrotic liver diseases. Liver Int. 2008; 28(8): 1065-79.

[16] Grundy SM, Brewer HB Jr., Cleeman JI, et al; American Heart Association; National Heart, Lung, and Blood Institute. Definition of metabolic syndrome: Report of the National Heart, Lung, and Blood Institute/American Heart Association conference on scientific issues related to definition. Circulation, 2004, 109: 433-8.

[17] ACE/ADA Task Force on Inpatient Diabetes. American College of Endocrinology and American Diabetes Association Consensus statement on inpatient diabetes and glycemic control. Diabetes Care 2006; 29: 1955-62.

[18] Kleiner DE, Brunt EM, Van Natta M, et al; Nonalcoholic Steatohepatitis Clinical Research Network. Design and validation of a histological scoring system for nonalcoholic fatty liver disease. Hepatology 2005; 41: 1313-21.
[19] Vanni E, Bugianesi E, Kotronen A, et al; From the metabolic syndrome to NAFLD or vice versa? Dig Liver Dis 2010; 42: 32030.

[20] Yilmaz Y, Senates E, Ayyildiz T, Colak Y, et al; Characterization of nonalcoholic fatty liver disease unrelated to the metabolic syndrome. Eur J Clin Invest 2012; 42(4): 411-18.

[21] Tarantino G, Colicchio P, Conca P, et al; Young adult obese subjects with and without insulin resistance: what is the role of chronic inflammation and how to weigh it non-invasively? J Inflamm (Lond) 2009; 6: 6 .

[22] Gressner OA, Lahme B, Demirci I, Gressner AM, Weiskirchen R. Differential effects of TGF- $\beta$ on connective tissuegrowth factor (CTGF/CCN2) expression in hepatic stellate cells and hepatocytes. J Hepatol 2007; 47: 699-710.

[23] Kovalenko E, Tacke F, Gressner OA, et al; Validation of connective tissue growth factor (CTGF/CCN2) and its gene polymorphisms as noninvasive biomarkers for the assessment of liver fibrosis. Journal of Viral Hepatitis 2009; 16: 612-20.

[24] Cayón A, Crespo J, Guerra AR, Pons-Romero F. Gene expression in obese patients with non-alcoholic steatohepatitis. Rev Esp Enferm Dig 2008; 100: 212-8.

[25] Tarantino G, Conca P, Riccio A, Tarantino M, Di Minno MN, Chianese D, Pasanisi F, Contaldo F, Scopacasa F, Capone D. Enhanced serum concentrations of ransforming growth factorbeta1 in simple fatty liver: is it really benign? J Transl Med 2008; 6: 72.

[26] Tarantino G, Savastano S, Colao A. Hepatic steatosis, lowgrade chronic inflammation and hormone/growth factor/adipokine imbalance. World J Gastroenterol 2010; 16(38): 477383.

[27] Wang Q, Usinger W, Nichols B, et al; Cooperative interaction of CTGF and TGF- $\beta$ in animal models of fibrotic disease. Fibrogenesis Tissue Repair 2011; 4: 4. 


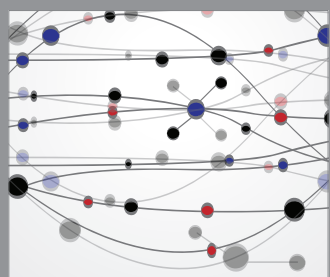

The Scientific World Journal
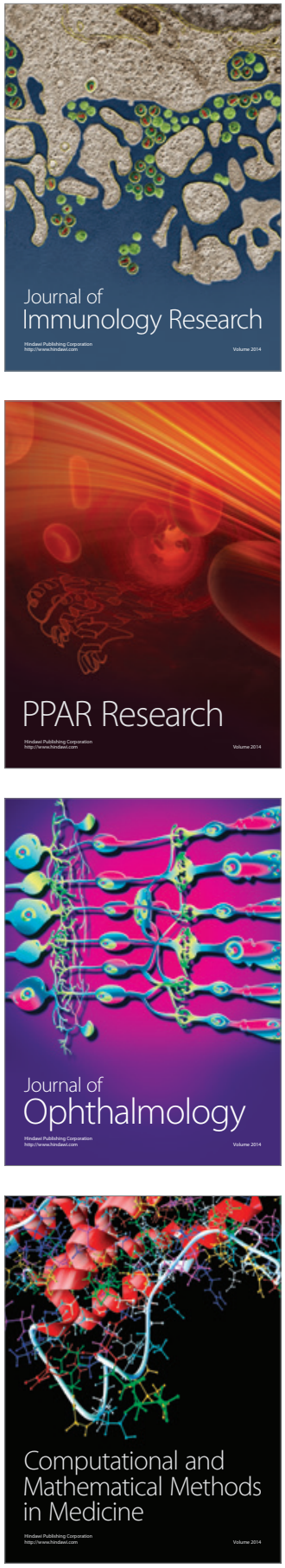

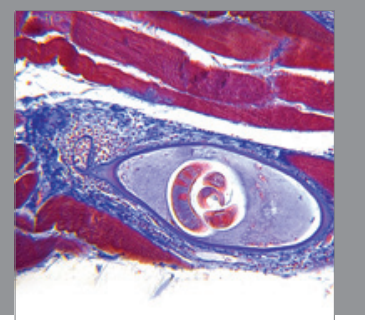

Gastroenterology

Research and Practice
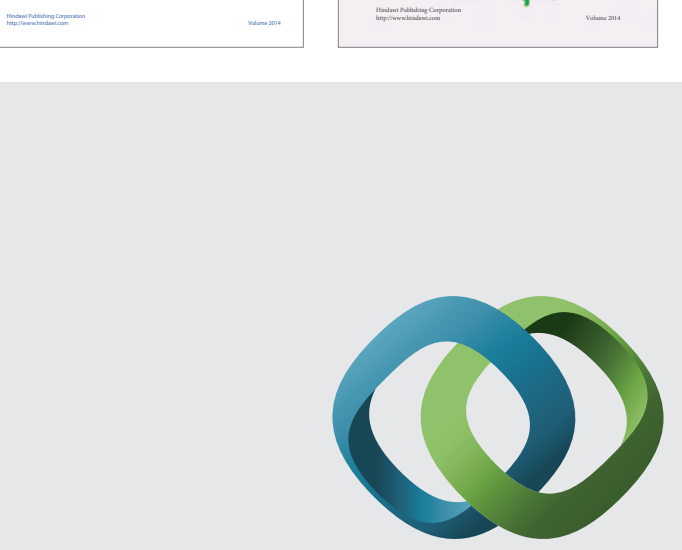

\section{Hindawi}

Submit your manuscripts at

http://www.hindawi.com
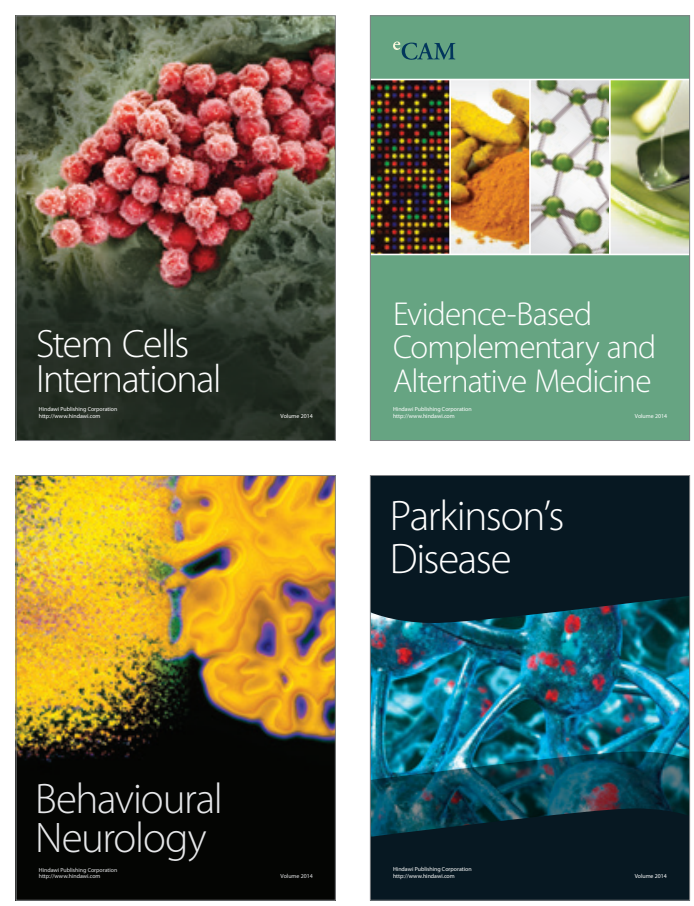

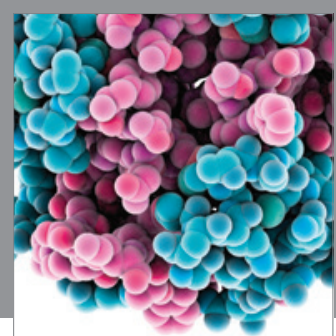

Journal of
Diabetes Research

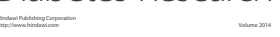

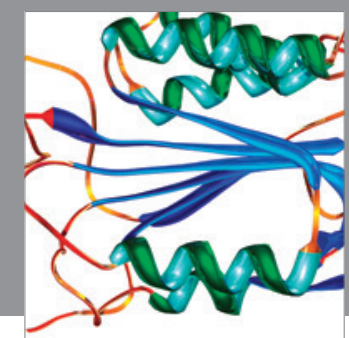

Disease Markers
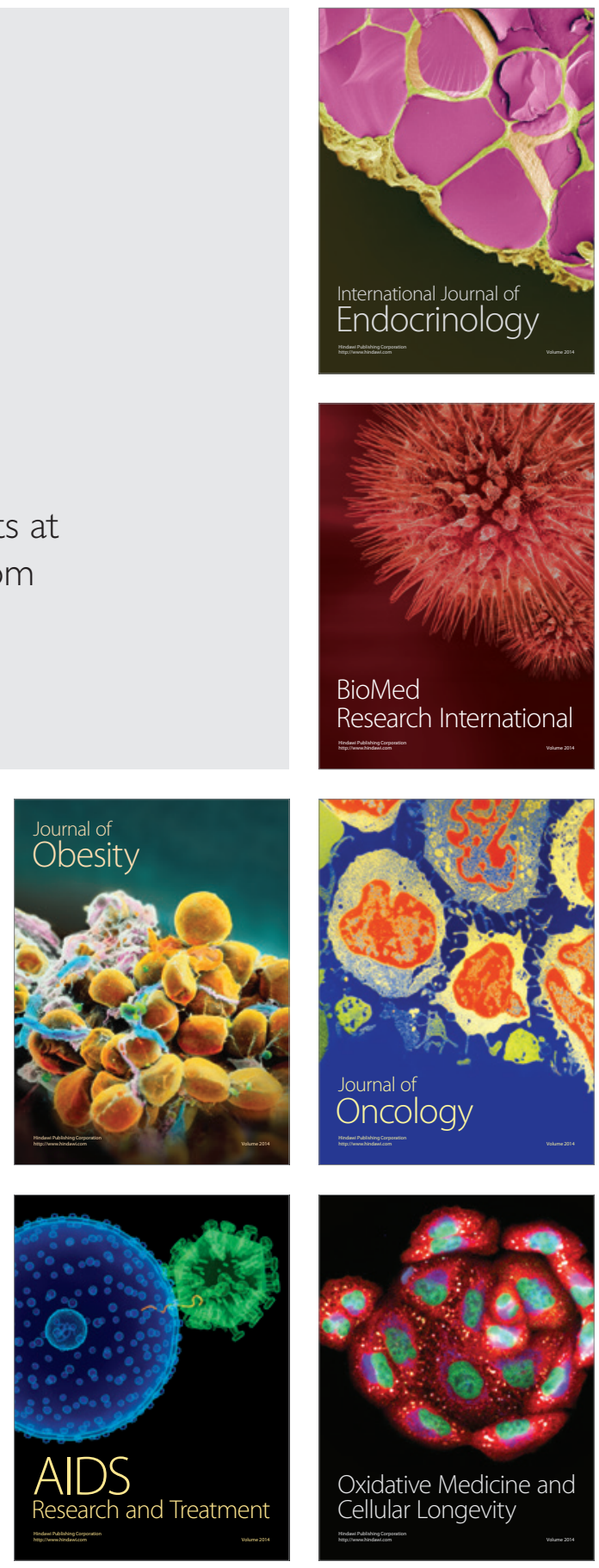